\title{
Memory programmes: the industrial retention of collective life
}

\author{
Samuel Kinsley \\ University of Exeter, UK
}

\begin{abstract}
This article argues that in software, we have created quasi-autonomous systems of memory that influence how we think about and experience life as such. The role of mediated memory in collective life is addressed as a geographical concern through the lens of 'programmes'. Programming can mean ordering, and thus making discrete, and scheduling, making actions routine. This article addresses how programming mediates the experience of memory via networked technologies. Materially recording knowledge, even as electronic data, renders thought mentally and spatially discrete and demands systems to order it. Recorded knowledge also enables the ordering of spatiotemporal experience both as forms of history, thus the sharing of culture, and as the means of imagining futures. We increasingly retain information about ourselves and others using digital media. We volunteer further information recorded by electronic service providers, search engines and social media. Many aspects of our collective lives are now gathered in cities (via closed-circuit television, cellphone networks and so on) and retained in databases, constituting a growing system of memory of parts of life otherwise forgotten or unthought. Using examples, this article argues that in software, we have created industrialised systems of memory that influence how we think about living together.
\end{abstract}

\section{Keywords}

industrialisation, landscape, memory, mnemotechnics, place, programming, spatiality, Stiegler, technology

\section{Introduction}

This article addresses the ways in which memory in collective life constitutes a particular spatial concern through the lens of 'programmes'. In particular, the role of electronic systems that record and store data about what we're doing, and where we are doing it, is interrogated as the quasi-autonomous agency of software. In this regard, and for the purposes of this article, I suggest that programming can mean two things: ordering, and so making things discrete, and scheduling, and so making actions routine. Thus, I want to think about how programming mediates the experience of memory via networked technologies that routinely act as an external memory: as prosthetic devices for the capture and retention of data about our lives. In particular, the aim of this article is to critically address this as a kind of 'industrialisation of memory', following the philosopher Bernard Stiegler.1

Increasing amounts of information about us is gathered using electronic devices, and we volunteer further information that is recorded by Internet service providers, search engines and social-networking systems. Many aspects of our collective lives are captured in cities (via closedcircuit television (CCTV), phone networks and so on) and retained in databases, as a growing system of memory of life otherwise forgotten or unthought. Software programmes thus have significant agency in the various ways in which we collectively communicate and remember. Materially recording knowledge (even as electronic data) renders thought mentally and spatially discrete and demands systems to order it. Indeed, those processes of ordering themselves play increasingly significant roles in contemporary collective spatial experience. Recorded knowledge also facilitates the ordering of time both as forms of history, and thus the sharing of culture, and as the means of anticipating and planning for futures. The logic of retained knowledge is thus 'programmatic' and has arguably become more so with the advent of software programmes, which augment our capacities to 'remember' information.

Cultural geography has broadly engaged with the theorisation and study of memory in terms of embodied sensibilities of recollection and forgetting and in terms of places charged with memory. In particular, memory has been addressed as an integral part of everyday life. ${ }^{2}$ As Jones $^{3}$ has noted, such research has focused upon a range of spatial registers, including national 
identity, ${ }^{4}$ its commemoration and contestation, ${ }^{5}$ urban space, ${ }^{6}$ historical landscapes, ${ }^{7}$ tourist landscapes ${ }^{8}$ and place and memorialisation. ${ }^{9}$ Within this work, there has been two principal foci: the psychological and somatic situation of memory as a capacity, and particular landscapes or spatial formations (memorials, monuments-both naturally occurring and human-made) that function as shared symbolic repositories - kept alive through cultural activities and traditions. The fact that contemporary digital technologies mediate increasing aspects of our collective lives both challenges and develops such understandings of memory. The aim of this article is to interrogate some key elements of how software has become a means of 'industrialising' memory. This industrialisation of memory involves conserving and transmitting extraordinary amounts of data, captured and volunteered in everyday life, and operationalising it in large-scale systems - constituting novel sociotechnical collectives which have begun to influence how we perform our lives such that they can be recorded and retained.

To investigate the programmatic nature of our mediatised collective memory, this article is structured in three parts. In the following, section 'Industrial-memory apparatuses', a number of technologies are explored as means of capturing, operating upon and retaining our everyday activities in 'industrial-scale' systems of memory. Particular attention is paid to the quasiautonomous agency of these systems, that appear to operate at a scale and speed that exceeds a human capacity of oversight. In section 'Mnemotechnics', the mnemonic capabilities of networked technologies of digital mediation are brought into focus to be examined as 'mnemotechnologies', technologies and technical supports that both support and reterritorialise what we collectively understand about our everyday lives. The conclusion considers how an 'industrialisation of memory' both challenges and transforms the ways in which we negotiate the spaces of collective life.

\section{Industrial-memory apparatuses}

The 20th century is the century of the industrialisation, the conservation and the transmission - that is, the selection - of memory. This industrialisation becomes concretized in the generalisation of the production of industrial temporal objects (phonograms, films, radio and television programs, etc). ${ }^{10}$

From governmental systems for taxation and welfare to supermarkets, banks and creditscoring agencies, many aspects of our lives are being monitored and recorded through the proxy of our pecuniary activities. CCTV networks, transport ticketing and trafficmanagement systems retain traces of our travel patterns. We volunteer further information to search engines and social media, and we have recently learned much of these data have also been captured and stored by government security agencies. ${ }^{11}$ Nevertheless, there is an equally 'hyper-consumerist exploitation of data'.12 Many aspects of our lives are collected in databases variously owned by private and public organisations and institutions. Constituting a growing system of memory - a memory of parts of life that might be otherwise forgotten or unthought. It also facilitates a perpetual operation on memory, iteratively reterritorialising what is understood about our lives. The software programmes that drive digital media, and those that create them, thus have significant agency in the ways we collectively communicate and remember. What is collected is retained and also transmitted - folded into other datasets and utilised for civic and commercial purposes. In this section, I want to focus on systems of mediated memory activities that are being constituted through networked technologies and the software that enables them to function.

We might think about such systems in several ways. The capturing of data for retention constitutes what Kitchin and Dodge call 'capta': 'units . . . selected . . . from the sum of all potential data ... [They are] what is selectively captured through measurement'. ${ }^{13}$ We can be passively enrolled or actively enrol ourselves into systems that constitute capta. For example, CCTV systems are forms of passive collection that do not require any interaction with those being surveilled. ${ }^{14}$ By contrast, social-networking systems function, mostly, through voluntary contribution insofar as they require users to post information. Capta collection activities thus feature both explicitly and implicitly in everyday life activities.

Capta collection creates systems that blur the distinction between individual and collective. Individual records of activity are kept, where they provide value, but those individual records are always already a part of much larger aggregated systems, which retain a collective memory of activity - statistically derived averages of activities of people 
who are variously grouped. ${ }^{15}$ For example, e-commerce websites with 'recommendation systems' use both individual purchasing histories and average patterns of purchasing (derived from all of the records of consumers in the system) to offer recommendations. Individual traces of activity, retained outside of the more commonly discussed somatic memory, are, in this sense, never left alone, they are selected, aggregated and transformed to produce forms of collective memory - something like a memory of habits.

As others have variously observed, ${ }^{16}$ these industrial capta-gathering systems have significant implications for the understanding and study of privacy and surveillance and the various institutional and territorial legal processes governing such systems. ${ }^{17}$ While such considerations fall outside of the scope of this article, it is worth noting a few things in passing: First, what constitutes 'public' and 'private' data in the systems discussed here, and thus the definition of surveillance, is blurred. Technologies are developed and adopted at a pace that has made it difficult for social norms of privacy to adapt. ${ }^{18}$ For example, we increasingly volunteer relatively personal data to social-networking systems that have ambiguous privacy settings, so it can be surprising how 'public' your data can be. Second, the systems discussed here are of significant interest to social scientists precisely because of their scale and reach: they have large populations of subjects/users and lots of data about them. However, performing research with such data, and the companies that own them, can pose significant questions about ethics. ${ }^{19}$ Third, the systems discussed here rely on an increasing number and scale of data centres with a capacity for interconnection through international telecommunications infrastructures to large numbers of portable and embedded devices that has transformed their scope and reach. Physical location determines the territorial jurisdiction for the governance of not only the equipment but also the data stored therein, determining how that data can be used - often in ways the subjects of that data may not know or desire. ${ }^{20}$

To explore the properties of what has been proposed as an emerging system of industrialised memory, the rest of this section will focus on three particular examples. First, a well-established supermarket-loyalty-card system is interrogated as a rather opaque system that operates on vast stores of aggregated and individual 'capta' to both predict and influence purchasing behaviour. Second, Facebook is discussed in relation to the ways in which volunteered 'capta' are stored and represented in 'timelines' that constitute a peculiar topology. Third, and finally, the increasing array of capta-collection systems in cities is investigated as repositories intended to constitute what has been referred to as the 'real-time' or 'smart' city.

\section{Memory consumption: 'every little helps'}

During the 1990s, a number of retailers sought to form ongoing, intimate, relationships with consumers. Loyalty cards remain central to 'customer relationship marketing' strategies, forming sophisticated assemblages, including call centres, websites, data centres and databases, product warehouses and supply-chain-management software, tills, printing facilities and the materials they produce and various analytical techniques to coordinate these 'customer relationship' activities. The claim for such systems is that retailers 'know' consumers and respond to them individually, the desired result of which is apparently 'deeper' relationships and the formation of 'bonds of loyalty'.21

In 2011, Tesco were the largest UK retailer, and the third largest in the world. ${ }^{22}$ One of the largest private-sector employers in the United Kingdom, Tesco purportedly takes one in every seven pounds spent in UK shops. ${ }^{23}$ Tesco argue that their success is due to 'listening' to their customers:

Our new conversation with customers ... is about listening to what they want, to how they're living their lives today, and then adapting and building the business accordingly: as we have said for years, 'Every Little Helps'.24

As Antony Beckett suggests, 'the notion of listening is central to Tesco's explanation of their success and ... that strategy is captured in their advertising strapline "Every Little Helps"'. ${ }^{25}$ The 'listening' at the heart of this venture is not a one-to-one mode of listening but instead a 'listening' to, and remembering, the vast amount of data that they collect, every day, 
through their 'Clubcard' system: 'Thanks to Clubcard ... we have unique insights into how our customers' behaviour is changing'. ${ }^{26}$

Launched in 1995, Clubcard is one of the largest UK loyalty-card schemes. ${ }^{27}$ Tesco sends vouchers to the more than 16 million UK Clubcard-holders, as well as money-off (datelimited) coupons that are based upon their spending habits and the spending habits of the lifestyle groupings by which Tesco categorises its customers. ${ }^{28}$ Thus, the 'Every Little Helps' promise is ambiguous. Tesco suggest they 'listen' to customers, remember their choices and make goods available, and cheaper, at particular times and in particular places. Yet, it is clear from Tesco's own 'Media Team' - which sells access to these data to third-parties ${ }^{29}$ - that Tesco use these data to position certain kinds of consumer behaviour as a norm for other consumers to follow: ' Clubcard media enables brands to: Talk directly to your existing shoppers, retain loyalty and grow their spend [and] Acquire prospective customers who are identified as potential trialists based on products they normally buy'. 30

According to a cofounder of DunnHumby (the data-mining company that developed Clubcard, now owned by Tesco), the resulting 'customer relationship model' known as Tesco ‘Customer Lifestyles' 31

is ultimately about trying to understand factors that drive shopping behavior, . . . together with measurement of Tesco's share of a customer's wallet or purse . . We wanted to capture more spend from each customer, and nudge them into buying products from Tesco that they might buy elsewhere. ${ }^{32}$

A detailed longitudinal dataset has been and continues to be accumulated that operates at both the level of detail of individual consumers and also at the level of aggregated market 'segment' categorisations, configured according to a typology of consumers. ${ }^{33}$ This is, of course, more than a log of activity. The capta stored by Tesco are continually analysed in order to influence future behaviour. The detailed records of individual and aggregated consumer activity become the object of calculation according to particular kinds of profiling, accomplished through algorithms.

Clubcard began with segmentation through traditional profiling methods, extrapolating from focus-group feedback combined with actual purchase data. Since 2001, with lowering technical costs, the whole dataset of more than '104 billion rows of data stored at any one time 34 is mined for the purchasing patterns of individuals and their responses to personalised marketing efforts. The growth of the dataset and the speed of harvesting and processing data allow algorithms to iteratively refine typologies of consumers, accelerating attempts to influence shopping habits. The feedback between the growing digital 'memory' of Clubcard databases and customer offers constitutes consumers as an evolving entity: 'The impact of marketing efforts can now be minutely recorded and analysed on an individual, store and geographic [territory] basis'. ${ }^{35}$

The Clubcard databases and their use in profiling customers to intervene in their daily habits produce kinds of commercial spaces, evident in two ways. First, particular kinds of commercial spatial experience interconnect supermarkets, homes and websites and apps (through Internet-connected devices). Timespaces of consumption are not necessarily specific to topographic locations. The place of 'convenience' shopping is (and has been for some time) untethered from the 'bricks and mortar' shop. ${ }^{36}$ Instead, it is topologically positioned between websites, databases and data warehouses; banks and payment networks; shops, homes and so on, often outside of traditional opening hours. Into such assemblages are enfolded detailed and increasingly intimate capacities of memory: of preferences (perhaps even desires) and habits.

Second, the fast-paced data gathered, minute-by-minute, about consumers and the attendant, more-sedately generated, data concerning shop infrastructures and environs are shaped by Geographical Information Systems (GIS). Indeed, it is through the combination of in-house data and those derived from commercial geo-demographic segmentation systems (a combination of socio-economic data with GIS facilitating analyses of particular market segmentations - such as CACI's ACORN, Experian's Mosaic and Compusearch's PRISM) that supermarkets decide on the location of stores. ${ }^{37}$ Such systems generate peculiar boundaries across territories, as represented in the GIS models manipulated by Tesco (and many others), that transform the uses of space - with the models pointing to the location of a superstore in a particular location, rather than any other, based upon segmentation analysis. 
Through ever-expanding databases and algorithms that continually analyse them, Tesco can perform iterated 'experiments' to refine segment typologies and strategies for targeting them. The 'geography' within such databases is an indexical attribute, organised at normative scales (such as store, post code, city and so on); it is one of many lines of segmentation, serving the targeting of offers, advertising campaigns and delivery of goods. The geographical imaginary Clubcard invokes is of populations of consumers, segmented by lifestyle preferences and socio-economic factors, distributed and delimited (or 'bordered') through particular categorisations of space. The consumer is thus enrolled into an industrial system that retains habits of consumption in significant detail, both at an individual and collective scale, and operates on that historiography in order to influence prospective future habits. ${ }^{38}$

\section{Performing a social graph}

Online social-networking systems, such as Facebook and Twitter, are repositories of quotidian reportage of everyday activity, from birthday wishes to holiday snaps, marriage announcements and memorials to lamented friends and relatives. ${ }^{39}$ Facebook in particular has encouraged a systematisation of peoples' social lives mediated by their platform. Users enrol themselves into 'networks' associated with institutions and workplaces, subscribe to 'pages' concerning their interests, play games together, organise 'events' and even buy and sell their possessions. ${ }^{40}$ Facebook's databases retain each activity, forming a growing repository of associations between people and other entities. Facebook uses this vast databased representation of users' mediated lives to target advertising at them according to patterns in data they themselves have volunteered. Furthermore, through the Facebook 'platform', launched in 2007, this repository of data is for sale, and third-party developers are able to integrate their own sites and services with the 'platform'.

At the 2010 Facebook developer conference, f8, Facebook launched the 'Open Graph' protocol, developed to facilitate connections between people, places and things, or their media representations, on Facebook. ${ }^{41}$ Open Graph consists of the protocol: a system of rules for the connection of entities in the database; an Application Programming Interface (API): a software gateway for any other online object or system; and what are called 'social plug-ins' - principally the now-ubiquitous 'Like' button. Open Graph enables Facebook to capture, retain and process user data across the whole web, not only within the bounds of the Facebook website, through the implementation of the API and social plug-ins.

Facebook developers refer to the networks of associations mapped through Facebook as the 'social graph'. 'Graph' refers here to the topological structure of 'nodes' within the network and 'edges', which are the connections between them: 'nodes refer to individual users and edges to the so-called friendship relations between users'. ${ }^{42}$ However, human relations are only one among many kinds of edges in Facebook's graph: nodes can also refer to other entities, such as companies, schools, products, events, songs, topographically defined locations and so on. The definition and ordering of these edges is governed and maintained by the Open Graph protocol and associated algorithms that form a central part of Facebook. This is a world-ing: both a modelling of and intervention into the forms of spatial experience of its users. Facebook is thus proactively seeking to constitute, albeit in a reductive and commercialised manner, what Massey calls a 'global sense of place': 'a particular constellation of social relations, meeting and weaving together at a particular locus'. 43 What Open Graph convenes is a topological model of everyday (mediated) life, which is always being captured and retained.

Whereas Facebook was initially a singular website, with representations within it of other sites and entities (from companies to products and so on), Open Graph enables Facebook to be an infrastructure for connecting entities, however they are represented online. Thus Open Graph is what Bucher calls 'a centralized architecture that generates value by decentralized social action'.44 For Facebook, the API and social plug-ins are 'edge creating devices', facilitating capta harvesting by the Facebook platform. Open Graph thus constitutes a form of memory not only of the encoded representations of entities (people, organisations, places, things and so on) but also of associations between those entities, a kind of topological memory.

The year after Open Graph was launched, at the 2011 f8 conference, Mark Zuckerberg, $\mathrm{CEO}$ of Facebook, gave a keynote presentation introducing further changes to the platform. ${ }^{4}$ 
In particular, Zuckerberg outlined changes to the organisation of users' profiles as a historiographic (or perhaps hagiographic) 'timeline' and updates to Open Graph, with more emphasis on how Facebook links with other systems. Open Graph initially relied upon modelling relationships through explicit interactions between entities represented within Facebook, particularly via the 'Like' button. The revised Open Graph includes a semantics of interaction to accommodate an implicit, or passive, recording of activity. Verbs such as 'read', 'watch', 'listen' and 'buy' were introduced to articulate a 'frictionless sharing' of activities mediated through systems interconnected with Facebook through Open Graph.46 For example, when a user reads an article using a newspaper app that is connected to Facebook, that user's timeline is updated to reflect that '[user name] has read [article name]'. Topographical location can be appended to such activities too: '[user name] is/was in/at [location]'. The topographical location is merely another point of capta, and thus another entity in the database that can generate edges.

Facebook, like other capta-harvesting 'social' systems, has become a system for capturing and in some way 'remembering' the various activities of everyday life, modelled as relationships (edges) between encoded entities (nodes). Facebook as an interface to social activities is also, importantly, a representation of those activities and the relationships they imply. In order to sort, prioritise and display 'timelines' and 'news feeds', Facebook has integrated a set of algorithms within Open Graph referred to as 'EdgeRank'. The purpose of EdgeRank is to sort and rank the relative importance of 'edges', relationships between nodes in the database (people, organisations, places, etc.), in order to prioritise the visibility of particular 'events'. Thus, every time an interaction happens within Facebook - a user posts something, mentions another 'node' and so on - EdgeRank assigns values to the relationships implied (the edges). ${ }^{47}$ Through Open Graph and EdgeRank, Facebook is not only an industrial-scale system that retains many aspects of its users' lives, it is also, perhaps more significantly, a system for the recollection of that 'memory', translated through a programmatic logic. The performance of spatiality inferred by Facebook's Open Graph and EdgeRank can be accordingly thought of as a kind of programmatic or mechanistic topology, every-thing (every data point) consists in relation to others. There is no presence and absence, merely different kinds of relation.

\section{Tracing the city}

There has been a growth in the popular discourse and policy rhetoric concerning the governance and management of cities through network technologies. With declining costs of technological devices and the growth of embedding information and communication technologies (ICTs) into urban infrastructures and street furniture has come the proposition of the 'smart city'. The moniker 'smart city', as a form of discursive regime, freights a number of interconnected discourses that justify and perpetuate particular understandings of what constitutes the 'smart-ness' of an urban environment, the socio-spatial conditions that can enable its development and who has the authority to name a city 'smart'. ${ }^{8}$ These discourses include commercial agendas for 'Smart Cities', aggressively marketed by corporations like Cisco, IBM and Siemens, among others, to sell 'intelligent' automated systems to manage urban utilities and infrastructures ${ }^{49}$ future-oriented research agendas for the development of ubiquitous computing to enable 'smarter' ways of living 50 and emerging systems of technocratic (urban) governance. ${ }^{51}$

The capabilities for creating 'smart cities' have developed in parallel and in relation to the development of technologies for large-scale collection, storage and processing of data.52 Whereas, as Harvey Miller suggests, ${ }^{53}$ much of what we know about cities has been derived from specially commissioned studies characterised by data scarcity, the capacities of embedded networked technologies for the urban environment are marketed as a means of large-scale, ongoing data collection. ${ }^{54}$ Networked infrastructures are thus characterised as a means for 'urban informatics', a 'smart' and real-time system for governing cities. Alongside civic and governmental applications for such technologies, many commercial applications have been conceived for the monitoring of populations for targeting advertising. If the examples of loyalty cards and social media are largely concerned with the industrialisation of memory as a capture and retention of individual activities, then the emergence of cityscale 'big data' systems constitutes a different kind of industrial-scale memory principally concerned with aggregated populations: something like a 'municipal memory'. 
As Kitchin notes, there has long been a production of large datasets for marketing, distribution and sales as well as for the purposes of governance. However, these datasets are not generated continuously, frequently rely upon sampling, often aggregated in broad geographical areas and so function as coarse snapshots. ${ }^{55}$ What constitutes contemporary 'big' data has not been clearly defined, but very broadly, it can connote datasets requiring bespoke systems for collection, processing and storage. Furthermore, Kitchin has identified some of the definitions of 'big data' found in relevant literature as very large in volume (petabytes of data), high in velocity (created in real-time), exhaustive in scope (striving to capture entire populations, or at least very large sample sizes), very detailed in resolution, and relational in nature, enabling the conjoining of different datasets. ${ }^{56}$ In addition to these factors, innovation in code and programming languages, and the ontologies or schema by which they are defined, has constituted 'metadata' formats - data that describe data - to facilitate interoperability through translation and transformation between code types.

There are a number of modes of data collection that undergird the emergence of what is being called 'smart' city infrastructure, that illustrate the scales - of computation, data, labour, infrastructure, topography and so on - at which 'urban informatics' is required to operate. It is the combination of not only broadening the resolution, scope and scales but also the speed of data collection that facilitates the institution of an emerging municipal memory. Kitchin articulates a typology of three sources for 'big' data that (can) drive 'smart city' systems: 'automated', where data are collected by software-driven systems - such as Automated Number Plate Recognition; 'directed', where data are collected by systems controlled by a skilled operator - such as CCTV; and 'volunteered', where data are provided by those previously surveilled, voluntarily, perhaps in exchange for value provided by a service based on those data - such as social media, like Facebook.

While 'directed' systems for harvesting capta have a long history - we might, for example, include censuses in this category - the scale and sophistication with which contemporary automated and volunteered 'big' data collection is taking place is relatively novel. 'Big' datasets have been made possible by the inclusion of techniques to embed individual and traceable identifiers on and into everything from public transit tickets (e.g. the London Oyster card) to cars (number plates), networked sensors distributed into the city to report back data ${ }^{57}$ and a shift in culture towards a tolerance for making previously private activities conspicuous through personal technologies (such as location-based services like Foursquare). This combination of data-collection systems has been envisioned as 'constellations of instruments across many scales that are connected through multiple networks which provide continuous data regarding the movements of people and materials' 58 that, importantly here, is retained and stored constitutes a significant aspect of an industrialisation of memory.

The kinds of automated systems being built into the everyday urban environment are not limited to the provision of services or the governance of public space but also include those specifically designed to put urban populations under surveillance for commercial purposes. There are systems where a form of surveillance can arise as a by-product: data are collected for the operation of a system that can then be repurposed by virtue of their metadata. For example, public transit systems increasingly operate with individualised 'smart' cards, with a unique identifier encoded into them, for payment purposes, which facilitates a form of tracking. In addition, processing pre-existing datasets to infer further information, such as location, there are also technologies for which surveillance for marketing and sales purposes is the principal goal. A number of digital systems are being inserted into everyday spaces that attempt to calculate our bodily dispositions for commercial gain. For example, the company QuiVidi have created a system 'automated audience measurement' system, 'VidiCube', that purportedly can track people near billboards using cameras to discern if and how long people look at adverts, and demographic distribution (specifically age and gender, with scope for further categorisations) of the 'audience'. ${ }^{59}$ This technology is currently being implemented by a British company, Amscreen, specialising in in-shop-advertising screens to be used in forecourt and retail-convenience stores, leisure centres and healthcare waiting areas. ${ }^{60}$ The 'Footpath' system created by Path Intelligence uses passive mobile phone signal detection to track movements through shopping centres in order to track consumer behaviour. ${ }^{61}$ Similarly, the suite of tools created by ShopperTrak uses both video footage and the electromagnetic communications systems commonly used by smart phones to track consumer behaviour. These tracking capta are then combined with sales data to provide 
analytics for how long people dwell in a shop, queue management, customer loyalty, effective use of labour and how these variously correlate with sales. ${ }^{62}$ These systems have been implemented by in a number of shopping centres across the world. 63

Through the systems that are being increasingly installed over large topographical (urban) areas and potentially collecting very large quantities of capta, detailed representations of urban populations and spaces are made possible. Furthermore, the interoperability of datasets through metadata makes 'markets' of data possible, and enables even greater detail. These 'big' data stores can be processed in order to feed back relevant information to a given population so that they can benefit, such as for planning travel. However, such detail also enables previously ambiguous spaces to be transformed into spaces of highly targeted advertising. What I have tentatively called municipal memory then, is not only, or necessarily, large archives or databases of a huge numbers of individuals' behaviours, updated in real-time, but also, due to the scope, scale and interoperability involved, an emerging form of collective memory, in which the urban subject is simultaneously conceived of as both singular and multiple, individual and municipal.

This section explored an emerging assemblage of mediated memory activities constituted through networked technologies. This assemblage involves the capture and retention of information, increasingly in real-time, about us as both individuals and populations, collected passively, automatically and by our volition, and aggregated and concatenated via metadata. Collectively, these memory apparatuses facilitate large-scale operations on what is remembered about us, how we can recall it and to what ends it is put to use, commercially and privately. In order to interrogate these industrial-memory apparatuses, the next section develops an understanding of memory as a prosthetic capacity through the conceptualisation of 'mnemotechnics' by the philosopher Bernard Stiegler.

\section{Mnemotechnics}

We exteriorise ever more cognitive functions in contemporary mnemotechnical equipment. And in so doing, we delegate more and more knowledge to apparatuses and to the service industries that network them, control them, formalise them, model them and perhaps even destroy them. ${ }^{64}$

In the Phaedrus dialogue, Socrates argues that the exteriorisation of memory, in the form of writing, is both a loss of memory and of knowledge - a loss, one might argue, that we experience on a daily basis in the contemporary epoch. Equally, in the progressive industrialisation of text, as print then its digitisation and subsequent transmission via the Internet, following Bernard Stiegler, the exteriorised human memory 'seems to have become something we can reactivate and access ad infinitum'.65 Through his articulation of a technogenetic understanding of the human, ${ }^{66}$ Stiegler provides a means of critically engaging with the 'industrial model' through which memory undergoes a fundamental transformation. This section explicates and then applies Bernard Stiegler's philosophy of technology and memory to critically engage with the industrialisation of memory explored (above) as the creation of an assemblage of industrial-memory apparatuses.

We can begin with an understanding of technics as the co-constitutive relation between 'the human' and 'the technical'. As both James Ash and I have outlined elsewhere, ${ }^{67}$ for Stiegler, it is through the exteriorisation of thought, through language and gesture, that we understand our internal conscious processes and this exteriorisation is achieved through technologies of language and writing. There is accordingly an irresolvable contradiction or absence of origin of the human in this relationship of exteriorisation, the human does not come before the technical and vice versa, they are co-constituted and continue to be so. Stiegler argues that ' $[\mathrm{w}]$ hat is exteriorised is constituted in its very exteriorisation and is preceded by no interiority: this is the logic of the supplement'.68 As Stiegler argues, ${ }^{69}$ 'technics is the horizon of all possibility' and an aporia of origin.

A mental reality, or a 'technical mentality' following Gilbert Simondon, ${ }^{70}$ can thereby be 'projected onto a support that is neither cerebral nor psychical but rather technical', which Stiegler calls the process of 'mnemotechnics' ${ }^{71}$ Technics accordingly is the constitution of the experience of temporality as the relation between the body, technology and the environment. Stiegler suggests these forms of 'retention' precede us and yet they are a part of us - there are 
forms of retention that were created long before the birth of an individual and yet that person can access them as a form of 'cultural memory'.72

Drawing upon Husserl's account of the consciousness of temporality constituted by retention and protention ${ }^{73}$ Stiegler calls the materialisation of thought, exterior to the mind and body, 'tertiary memory'. For Husserl, retention is considered in two parts: primary and secondary retention. Primary retention is the fixing of experience in the immediate conscious. Secondary retention is the weaving together of the various memorial contents that make up what we call memory. Together with these forms of retention as a part of ongoing conscious experience, we project forward and anticipate, forming 'protentions'. ${ }^{74}$ Departing from Husserl, Stiegler includes 'tertiary retention' as the mnemotechnical exteriorisation of secondary retentions. However, because we are born into a world already filled with technical objects 'tertiary retention always already precedes the constitution of primary and secondary retention' ${ }^{75}$ With this exteriorisation of thought comes its material spatialisation, as it is recorded in material form and, rendered discrete as prosthetic memory. One might suggest that when graphic practices produced spatially fixed pictures and writings (as monuments, carvings, painted walls and so on), such forms of exteriorisation, when collectively constituted, historically composed the kinds of 'pause' or 'permanence' that constitute place for Tuan and Harvey respectively. ${ }^{76}$

Exteriorisation also involves an anticipation of its further use, folding into processes of protention and thus stimulating forms of spatial imagination. The ongoing development of the human is thus always and already in relation to the technical, and what Stiegler calls the 'organised inorganic matter' of tertiary retention. The mnemotechnical is transformed, deepened and rendered more complex with our ongoing development. Primary and secondary retention are increasingly of experiences of mnemotechnical forms, especially media. Thus, Stiegler's supplement of 'tertiary retention' to Husserl's phenomenology is of significant importance for thinking the phenomenality of a range of collectively mediated phenomena. In particular, in relation to the programmatic capacities of digital technologies, exteriorised 'tertiary memory' is not peculiar to an individual but shared and highly reproducible.

Spatiotemporal distance between those recalling and what is recalled is collapsed, and a memory is iteratively reterritorialised in the moments of its recollection, over-determining it with the metadata of capture, storage and retrieval. The phenomenality of a given experience is necessarily over-coded with chrono-referential and geo-referential data, specified by technical infrastructures: audio, images and video become geo-coded as a matter of course, with many devices appending global positioning system (GPS) coordinates into their metadata by default. While the immediate spatial experience of capturing memories as digital photos and so on is not particularly different from the 'analogue' experience, it is the instauration of widespread, faster and increasingly automated capture, storage and recollection processes, programmatically, that calls for further study.

In what remains of this section, I want to use the idea of programmes to think through the ways in which the increasingly digitised mnemotechnical apparatus has constituted what Stiegler has addressed as an industrialisation of memory. ${ }^{.7}$ This industrialisation is largely concerned with what Stiegler identifies as an epochal shift away from a historical culture that has been rooted in the linearity of writing. Stiegler differentiates this historical culture from a currently emerging epoch

in which the retention of the past passes primarily through the technical systems of analogical ... and digital communications media and other technically mediated perceptions. ${ }^{78}$

If our experience of historical time, as the linear reasoning of phenomenological sensations of temporality, is fundamentally rooted in mnemotechnics, then, Stiegler argues, the flow of history itself is constituted by a process in which dominant technical systems develop and are accompanied by new cultural forms that are programmed by those systems. This programming is not only the mnemotechnical ordering of discretised information, historically as writing and perhaps more recently in the form of databases. Such a programming is also concerned with the routinisation of activity, of constituting rhythms by which activities are organised and comprehended. 
As addressed above, it is clear that we increasingly retain information about ourselves and others using digital media and volunteer yet more information that is recorded by Internet and media service providers, search engines, social media and retailers. Thus, many aspects of our lives become 'capta' in data stores and databases. This facilitates a kind of perpetual operation on memory, iteratively reterritorialising what is understood about our collective lives for various purposes in the ever-moving present.

These (mnemotechnical) media increasingly operate in the process of 'event-isation', ${ }^{79}$ intervening in our ongoing spatiotemporal experience and clearly reshaping the processes of retention. The effect of presence is manipulated by contemporary digital media: an experienced event and its capture in a mnemotechnical apparatus coincide in time, such that, simultaneously, digital technologies inaugurate a new collective, in the process of capturing, ordering and distribution, as well as individual experience of timespace as a departure from historicity. We might think here of the now-common sight of people at live events experiencing them through the lens of their camera-phones, simultaneously experiencing the moment and enframing and recording (perhaps even streaming) that experience for social media systems.

Social and spatial software programmes attempt to 'produce' timespace by selecting what merits identification as an 'event'. Information has value as the heirarchisation of 'what happens': By selecting what is called an 'event', the (software) programmes, and the commercial interests they represent, co-produce the access to 'what happens'. The Facebook 'news feed' is just such a quasi-automated system of selection of events. This is, of course, nothing new. Contemporary media co-produce what happens, for example, as 24-hour rolling news, and in this sense anticipate what is going to happen. This merely reflects the ways memory traverses primary and secondary retentions: 'the actions, decisions, facts and events through which one got here' do not remain in the present's past but always already preceded it - without determining it. 80

What perhaps is novel is that the widespread industrial systems of retention, and social media in particular, predetermine events in their encoded rules of functionality. When the conditions of memorisation, what Stiegler calls the 'criteria of effacement' - selection, retention-protention and ultimately attention ${ }^{81}$ - are all concentrated in one technoindustrial system, that system determines rules of participation and hence conditions retentional activities. Software, such as the mobile phone apps for Facebook, or Google Plus, and even the Tesco Clubcard - and the protocol-logical software infrastructure that interconnects them with many other systems - facilitate the apparently easy recording of activities and events. However, such software can predetermine the nature of such events. Users, or 'actors', 'anticipate the conditions of their acts' recordability and act according to the constraints of this industrial façade of time' and space. ${ }^{82}$ We have begun to organise how we address and perform activities according to how they can be captured using mnemotechnical systems.

Returning to the example of people at 'live' events simultaneously recording and experiencing the event through the mediation of a technical device such as a camera-phone, it is not only that the device is ready-to-hand, and thus used instinctively, but also that we are forming a habit of using such mediating devices (and the programmes that enable them) and assume their use when we plan to attend an event, or perform an activity. So, many of us convene our own spatialities of a given event with the criteria of its recording and sharing with digital media. We have internalised the logic of the 'criteria of effacement' to such an extent that it is woven through many aspects of our spatial experience. For example, when attending an event, we might (consciously or otherwise) select outfits because they are photogenic, pick spots to stand because they are good for photos and video or have a better phone signal for access to social media and so on.

Furthermore, the passive collection of data through the integrated systems of the APIs of social-networking systems like Facebook's Social Graph begin to ask questions about the scheme of retentional capture outlined in Stiegler's reading of Husserl. If activities are discretised at the very moment of action, without the need for somatic retention by the embodied user, the selection process from secondary to tertiary retention becomes shortcircuited. The increasing passive recording and sorting of mediated activities through the plethora of networked sensing, and recording apparatuses, therefore prompt interesting questions about the protentional force of the industrial fabrication of timespace. Such systems arguably suspend the possibility of distinguishing between an 'event' and its 
'capture', its induction into memory (whether primary, secondary or tertiary), or between its 'capture' and its 'reception' or recall..$^{33}$ Indeed, Stiegler argues that in such cases, 'these three moments coincide in a single spatiotemporal reality such that all delay, all distance, between them is eliminated' ${ }^{84}$ If historicity is the process of translating an event, its entering as data and then its reception or reading, it is a process of deferral (gaps of varying degrees between those steps). Such deferrals allow for deliberative processes of selection in the mediation of artefactual memory. Thus, the advent of network technologies that capture and transmit and facilitate 'recall' with only an infinitesimal delay between them (the speed of light) engage a different process of selection routines for the retention and reception of 'events'. Therefore, the programmatic industrialisation of memory, through the algorithms and protocols of digital media, not only operates in the post facto enframing and sorting of data for its transmission (by the Facebook 'EdgeRank' or Path Intelligence 'Footpath' algorithms for example) but also in the moment, by virtue of their use to capture and mediate in 'real-time'. This quasi-autonomous 'programming' of memory, through the opaque, large-scale and widespread systems discussed here, appears to operate at a scale and speed that exceeds a human capacity of oversight.

Following Stiegler then, and to conclude this section, we might begin to question how the shift towards the primacy of industrialised-digital memory is affecting our ways of understanding the past and anticipating a future and thus our geographic imaginaries and forms of spatial imagination. Furthermore, we might ask, with Stiegler, whether such processes have begun to 'inaugurate a different experience of time[space], [and] new and different mode[s] of [spatiality and] temporalisation' ${ }^{\prime} .55$

\section{Conclusion}

As the new digital mappings wash across our world, perhaps we should ask about the worlds that are being produced, ... the conceptions of history with which they work, and the forms of socio-political life to which they contribute..$^{86}$

The centrality of the exteriorisation of memory to contemporary experiences of everyday life and its transformation with and through digital media is notably under-discussed in geographical engagements with memory. Thus, many questions are implicated in the theorisation of an 'industrialisation of memory', presented in this article. Foremost among these questions, for cultural geographers, might be: 'What kinds of spatial experience does this industrialisation of memory produce or inhibit?' It is with the posing of this question that I wish to conclude this article.

The industrialisation of memory enabled through a proliferation of 'programmes' that collect and retain data in our everyday lives, as outlined here, asks questions of the tradition within cultural geographies of the positing of places and landscapes as spaces rendered distinct through an accumulation and concretisation of memory, in situ. This is not to say that with contemporary 'mnemotechnologies', we no longer form personal and embodied memories - far from it. It is rather to suggest that a significant technical apparatus plays an increasing role in mediating and supplementing such processes. Whereas many articulations of memory (in relation to the production of place and landscape) figure the subject as an author and convenor of memory in-place, industrial-memory apparatuses ask us to consider other forms of agency present in the 'memory work'87 that produces place. We can see how the industrialisation of memory might be understood as a system of flows, which sketches out the networks of relation between the various constituents of the processes of memorisation. Nevertheless, these systems are also, and always, reterritorialising both memorisation and recall. In this way, there is a kind of automatic and iterative concretisation of 'memory' and 'place' within the industrial apparatus of retention. The forms of programmatic memory I have described thus attempt to perform the kinds of 'pause' and 'permanence' Tuan and Harvey, respectively, ascribe to 'place', with the corollary that they are digital and so also both infinitely reproducible (thus the topographical locus is not necessarily materially fixed and can be multiple) and capable of performing radically different temporalities - which can be very quick (through rapid deletion) or iterative (in a cycling of capturing, processing and over-coding the 'same' memory).

If the urban landscape is increasingly mediated, and reshaped, with and through the industrial mnemotechnologies addressed in this article, how might we reconcile this with the 
focus in cultural geography on 'landscape as a concretisation and maker of memory'?88 This is, of course, a question with considerable scope, which demands significant further enquiry. However, by way of a conclusion and to begin to answer this question, I suggest taking two conceptual steps: first, to signal how we might read together established understandings of landscape and memory with conceptualisations of technically mediated spatial experience, and, second, to pose questions about how such a reading can accommodate the multiple forms of agency enacted in the industrial mnemotechnical systems addressed in this article.

First, while it is implausible to review the full gamut of landscape studies here, we might consider beginning this heretical synthesis of theories of landscape and mnemotechnics with Don Mitchell's reading of cultural landscapes in which he identifies two principal understandings: the 'epistemological landscape' - 'landscape as the material revelation of human practice and thought', 89 and the 'apocryphal landscape' - 'landscape as a way of seeing, especially a way of seeing that relishes the gaze, that asserts power by privileging perspectival vision, which, far from being a mere way of seeing, informs the actual, material making of places' .90

One might begin by applying such conceptualisations of landscape to the examples already addressed within earlier sections of this article. Thus, a material revelation of practice and thought might be understood in the guise of the production of 'software-sorted' spaces. For example, the layouts of supermarkets and shopping centres are continually transformed based on the analysis of patterns of consumption and parambulation within a given location. Furthermore, we might consider the placement of screen-based advertising and the kinds of adverts they display based on facial recognition data. We might move on to consider landscape as a way of seeing through the multiple gaze of various mnemotechnically augmented individuals and collectives. Returning to the capturing, or perhaps eventalisation, of a live music event addressed in the previous section, the singular gaze of an individual through the lens of a smartphone is rendered multiple in the transmission of what is recorded to industrial mnemotechnical apparatuses such as Facebook, thereby constituting something like a 'macro-collective' gaze. Such representations

arrange, order, include and exclude, they make knowable a space to everyone who might choose to look at these representations and also make it possible to compare it with another space... ${ }^{91}$

Whereas Hetherington describes, here, the refractive capacities of 'traditional' media such as text and photographs, digital media facilitate a pace and scope of a different magnitude. Thus, the 'macro-collective' gaze of digital mnemotechnical systems enables an iterative reterritorialisation through persistent operations on the representation(s) of a given landscape.

However, both of these understandings of landscape do not quite account for the variety of collective and quasi-autonomous agency of the systems of memorisation addressed within this article. It is necessary to understand landscape neither solely as the product of a privileged individual (human) perspective or, solely, as a depthless 'veil of symbols and significations', nor, we might add, as the geometrically defined topographical stratum of the 'base maps' of geoweb technologies. Following John Wylie ${ }^{92}$ and Rob Kitchin ${ }^{93}$ (albeit from rather different standpoints), we can understand landscape as a form of ontogenetic spatial experience:

landscape is neither simply seen nor seeing, neither an object seen by a gaze nor a particular way of seeing. It concerns also the immanent relation which inspires these orders. As the folding inflection between ontogenetic depth and actualised percept, landscape necessarily partakes of or enfolds both these orders, both an enabling potentiality and a witnessed array of seer and seen..$^{94}$

Landscape is a form of spatial experience that is 'beckoned into being through various practices and processes'. ${ }^{95}$ We can understand this beckoning as a form of transduction: 'a process of ontogenesis, the making anew of a domain in reiterative and transformative individuations ... [a] process by which things transfer from one state to another'.96 
Landscape, as transduced by the industrial systems of memory that undergird many aspects of life, is a 'metastable' experience - that is

a process that is in movement to the extent that it is: on the one hand, partially stable ... and able to maintain its form ... and yet, on the other hand, partially unstable, insofar as this form never ceases to become other than what it is. ${ }^{97}$

Landscape understood in this way consists in metastable geometries of power, 98 perpetual ontogenetic modulations of (human and non-human) materialities and sensibilities of spatial experience. Contemporary landscapes, at least those mediated by 'mnemotechnologies', are constituted as assemblages which involve the capture and retention of information, increasingly in real-time, about us as both individuals and populations, which is collected both passively or automatically and by our volition.

Second, given an ontogenetic understanding of space as transduced with digital media, we might form questions about how we, as cultural geographers, might address the various agencies of industrial-memory apparatuses within our understandings of landscape. It is possible, as many dystopian accounts of the increasing role of digital media in everyday life do, to imagine a flattened and homogenous form of mediated spatial experience - akin the kinds of non-places about which Marc Augé writes. ${ }^{99}$ However, the assumption of the homogeneity and stability of data gathered may not be necessarily born out in experience: different interpretations, data and their performance in capture and recall are part of broader interpretive networks. Indeed, as Mackenzie and McNally have argued, 'digital devices [and their attendant infrastructures] thicken as well as flatten worlds'.100 Nevertheless, the increased role of 'mnemotechnologies', employed knowingly and otherwise, invites searching questions about the kinds of spatial experience that are being transduced. How and what kinds of timespaces are being produced and performed with the range of quasiautonomous actors we have begun to discuss here? How can we address the transductions of spatial experience made capable by systems operating at rates (of speed and volume of capture) that are becoming difficult for us to oversee and within systems that are inherently opaque to their users? What does such a formulation of landscape do to the conventional idioms of self and landscape explored by cultural geographers?

The emerging industrial apparatuses for the capture, storage and transmission of memory demonstrate a potentially sizable shift in the ways in which we govern, negotiate and understand our collective life. On the one hand, they place the potential for an extraordinary level of control over what is remembered, how it is remembered and what influence this can have on contemporary socio-spatial experience - where we can go, with whom we communicate and so on. On the other hand, these 'mnemotechnologies' are beginning to open out not only the access to but also the creation of shared, collective knowledge across a diverse spectrum of lives. The landscape of collective urban life, arguably now more than ever, hinges on the metastability of increasingly large systems of the capture, retention and recall, and thus spatialisation in many guises, of knowledge. As a consequence, the nature of mnemotechnical apparatuses, the infrastructures and software that drive them, and the work they do in the world are in need of sustained critical attention.

\section{Notes}

1. B.Stiegler, Technics and Time, 2: Disorientation, trans. by S.Barker (Stanford: Stanford University Press, 2009); B.Stiegler, Technics and Time, 3: Cinematic Time and the Question of Malaise, trans. by S.Barker (Stanford: Stanford University Press, 2010).

2. See D.Atkinson, 'Kitsch Geographies and the Everyday Spaces of Social Memory', Environment and Planning A, 39, 2007, pp. 521-40; R.A.Dodgeshon, 'In What Way Is the World Really Flat: Debates Over Geographies of the Moment', Environment and Planning D: Society \& Space, 26, 2008, pp. 300-14; N.C.Johnson, 'Locating Memory: Tracing the Trajectories of Remembrance', Historical Geography, 33, 2005, pp. 165-79; S.Legg, 'Memory and Nostalgia', cultural geographies, 11, 2004, pp. 99-107; S.Legg, 'Reviewing Geographies of Memory/Forgetting', Environment and Planning A, 39, 2007, pp. 456-66.

3. O.Jones, 'Geography, Memory and Non-Representational Geographies', Geography Compass, 5, 2011, p. 877.

4. For example, J.R.Gillis, Commemorations: The Politics of National Identity (Princeton: Princeton University Press, 1996); A.Pred, The Past Is Not Dead: Facts, Fictions and Enduring Racial Stereotypes 
(Minneapolis: University of Minnesota Press, 2004); D.Tolia-Kelly, Landscape, Race and Memory. Material Ecologies of Citizenship (Oxford: Oxford University Press, 2010).

5. For example, S.Legg, 'Contesting and Surviving Memory: Space, Nation and Nostalgia in Les Lieux de Memoire', Environment and Planning D: Society \& Space, 23, 2005, pp. 481-504; K.Till, 'Places of Memory', in J.Agnew, K.Mitchell and G.Toal (eds), A Companion to Political Geography (Oxford: Blackwell, 2003), pp. 289-301; K.Till, 'Artistic and Activist Memory-Work: Approaching Place-Based Practice', Memory Studies, 1, 2008, pp. 95-109.

6. M.Crang and P.S.Travlou, 'The City and Topologies of Memory', Environment and Planning D: Society \& Space, 19, 2001, pp. 161-77.

7. V.Della Dorra, 'The Rhetoric of Nostalgia: Postcolonial Alexandria between Uncanny Memories and Global Geographies', cultural geographies, 13, 2006, pp. 207-39; V.Della Dorra, 'Mountains and Memory: Embodied Visions of Ancient Peaks in the Nineteenth Century Aegean', Transactions of the Institute of British Geographers, 33, 2008, pp. 217-32; L.Hill, 'Archaeologies and Geographies of the Post-Industrial Past: Landscape, Memory and the Spectral', cultural geographies, 20, 2013, pp. 379-96.

8. D.DeLyser, 'Romona Memories: Fiction, Tourist Practices, and Placing the Past in Southern California', Annals of the Association of American Geographers, 93, 2003, pp. 886-908.

9. G.C.Hoskins, 'Materialising Memory at Angel Island Immigration Station', Environment and Planning A, 39, 2007, pp. 437-55; K.Mitchell, 'Monuments, Memorials and the Politics of Memory', Urban Geography, 24, 2003, pp. 442-59.

10. B.Stiegler, "The Time of Cinema. On the "New World" and "Cultural Exception"', (trans. G.Collins) Tekhnema, 4, 1998, p. 106.

11. On 6 June 2013, The Guardian published the first stories based on the leaking of US National Security Agency documents by former intelligence analyst Edward Snowden, see G.Greenwald, 'NSA Collecting Phone Records of Millions of Verizon Customers Daily', The Guardian, 6 June 2013, <http://www.theguardian.com/world/2013/jun/06/nsa-phone-records-verizon-courtorder>. For a detailed timeline of the leaks and their coverage in the press, see "Timeline of Edward Snowden's Revelations', Aljazeera America, <http://america.aljazeera.com/articles/multimedia/timeline-edward-snowdenrevelations.html> (accessed: 1 June 2014).

12. B.Stiegler and C.Bastin, 'Bernard Stiegler: "l'emploi salarié va devenir minoritaire"', Interview, 13 June 2014, minoritaire_a551.html> $<$ http://www.wedemain.fr/ Bernard-Stiegler-l-emploi-salarie-va-devenir-

13. R.Kitchin and M.Dodge, Code/Space: Software and Everyday Life (Cambridge: The MIT Press, 2011), p. 261.

14. See S.Graham, 'Software-Sorted Geographies', Progress in Human Geography, 29, 2005, pp. 562-80.

15. This is, of course, the basis for Michel Foucault's proposition of governmentality: a calculative governance by institutions and procedures of populations through statistics that produces 'model' behaviour that becomes internalised as norms, see M.Foucault, 'Governmentality', in G.Burchell, C.Gordon and P.Miller (eds), The Foucault Effect: Studies in Governmentality (Chicago: University of Chicago Press, 1991), pp. 87-104; M.Foucault, Security, Territory, Population: Lectures at the Collège de France 1977-1978, trans. by M.Burchell (Basingstoke and New York: Palgrave Macmillan, 2007).

16. See S.Elwood and A.Leszczynski, 'Privacy, Reconsidered: New Representations, Data Practices, and the Geoweb', Geoforum, 42, 2011, pp. 6-15; Graham, 'Software-Sorted Geographies'; D.M.Wood and K.Ball, A Report on the Surveillance Society (London: Surveillance Studies Network, 2006).

17. For example, see S.Graham, Cities Under Siege: The New Military Urbanism (London: Verso, 2011); S.Graham and S.Marvin, Splintering Urbanism: Networked Infrastructure, Technological Mobilities and the Urban Condition (London: Routledge, 2001); S.McDowell, P.E.Steinberg and T.K.Tomasello, Managing the Infosphere: Governance, Technology and Cultural Practice in Motion (Philadelphia: Temple University Press, 2007).

18. Privacy has been variously discussed as the protection of 'personally identifiable information' (P.M.Schwartz and DJ.Solove, 'The PII Problem: Privacy and a New Concept of Personally Identifiable Information', New York University Law Review, 86, 2011, p. 1814), a practice and a process, rather than a state of being (A.Marwick and D.Boyd, 'Networked Privacy: How Teenagers Negotiate Context in Social Media', New Media \& Society. Epub ahead of print 21 July 2014. DOI: 10.1177/1461444814543995), and in particular a 'boundary regulation process' (L.Palen and P.Dourish, 'Unpacking "Privacy" for a Networked World', in Proceedings of the SIGCHI conference on human factors in computing systems, Fort Lauderdale, FL, 5-10 April 2003, pp. 129-36. 
(New York: ACM)) and so a maintenance of 'contextual integrity' (H.F.Nissenbaum, Privacy in Context: Technology, Policy, and the Integrity of Social Life (Stanford: Stanford University Press, 2010)). In terms of privacy in relation to surveillance, see P.Agre, 'Surveillance and Capture: Two Models of Privacy', Information Society, 10, 1994, pp. 101-27; C.J.Bennett, 'Cookies, Web Bugs, Webcams and Cue Cats: Patterns of Surveillance on the World Wide Web', Ethics and Information Technology, 3, 2001, pp. 195-208; J.Krumm, 'A Survey of Computational Location Privacy', Personal and Ubiquitous Computing, 13, 2009, pp. 391-99; D.Lyon (ed.), Surveillance as Social Sorting: Privacy, Risk and Digital Discrimination (London: Routledge, 2003); M.Gray, 'Urban Surveillance and Panopticism: Will We Recognise the Facial Recognition Society', Surveillance and Society, 1, 2003, pp. 314-33.

19. For example, a recent study conducted by data scientists at Facebook and Cornell University concerning the spread of positive and negative sentiments on Facebook has generated heated discussions about whether and how it is possible to gain informed consent in such studies, how and when forms of institutional oversight might come into play and whether the results of ethically questionable research should be published. See A.D.I.Kramer, J.E.Guillroy and J.T.Hancock, 'Experimental Evidence of Massive-Scale Emotional Contagion through Social Networks', PNAS, 111, 2014, pp. 8788-90.

20. For more discussion, see P.T.Jaeger, J.Lin and J.M.Grimes, 'Where Is the Cloud? Geography, Economics, Environment, and Jurisdiction in Cloud Computing', First Monday, 14, <http://firstmonday.org/ojs/index.php/fm/article/view/2456/2171>; W.Kuan Hon, J.Hörnle and C.Millard, 'Data Protection Jurisdiction and Cloud Computing - When are Cloud Users and Providers Subject to EU Data Protection Law? The Cloud of Unknowing', International Review of Law, Computers \& Technology, 26, 2012, pp. 129-64.

21. A.Beckett, 'Governing the Consumer: Technologies of Consumption', Consumption, Markets and Culture, 15, 2012, p. 2. See also: D.Peppers and M.Rogers, The One to One Future: Building Relationships One Customer at a Time (New York: Doubleday, 1993).

22. See Deloitte, Global Powers of Retailing 2013. Retailing beyond (London: Deloitte Global Services Ltd, 2013), p. 20.

23. See H.Wallop, 'Tesco Is Europe's Biggest Private Sector Employer', The Telegraph, 3 October $2011<$ http://www.telegraph.co.uk/finance/newsbysector/retailandconsumer/8802657/Tesco-is-

Europes-biggest-private-sector-employer.html>; BBC News, 'Tesco Market Share Dips below 30\%', BBC News, 31 January 2012, <http://www.bbc.com/news/business-16817254>; H.Wallop, '£1 in Every Seven Now Spent in Tesco', The Telegraph, 16 April 2007 <http://www.telegraph.co.uk/news/uknews/1548742/1-in-every-seven-now-spent-inTesco.html >.

24. 'Report from the Chief Executive' in Tesco PLC Annual Report and Financial Statements 2013 (Cheshunt: Tesco PLC, 2013), p. 3.

25. Beckett, 'Governing the Consumer', p. 6.

26. Tesco PLC Annual Report, p. 3.

27. Edwina Dunn, cofounder of DunnHumby, quoted in N.McElhatton, 'Case Study: Tesco', Direct Response, August/September 2002, p. 33.

28. See <http://www.tesco.com/clubcard/coupons/> and 'Tesco at a glance' in Tesco PLC Annual Report, inside cover.

29. See McElhatton, 'Case Study', pp. 33-4.

30. Tesco Media: 'Clubcard', < http://tescomedia.com/tesco-media-toolkit/clubcard/ >

31. See: C. Humby, T.Hunt and T. Phillips, Scoring Points: How Tesco Continues to Win Customer Loyalty (London: Kogan Page, 2007).

32. McElhatton, 'Case Study', p. 33.

33. See McElhatton, 'Case Study', pp. 33-4.

34. McElhatton, 'Case Study', p. 33.

35. Beckett, 'Governing the Consumer', p. 11.

36. For a review of geographical considerations of changing practices and locations of retails, see N.Wrigley, M.Lowe and A.Currah, 'Retailing and E-Tailing', Urban Geography, 23, 2002, pp. 18097.

37. See G.P.Clarke and S.Hayes, 'GIS and Retail Location Models', in G.Cliquet (ed.), Geomarketing: Methods and Strategies in Spatial Marketing (London: ISTE, 2006), pp. 165-86; G.Cliquet, 'Retail Location Models', in G.Cliquet (ed.), Geomarketing: Methods and Strategies in Spatial Marketing (London: ISTE, 2006), pp. 137-64. 
38. For discussion of the 'infrastructures of habit', see D.Bissell, 'Virtual Infrastructures of Habit: The Changing Intensities of Habit through Gracefulness, Restlessness and Clumsiness', Cultural Geographies. Epub ahead of print 4 April 2013. DOI: 10.1177/14744474013482812.

39. This shift in the performance of collective memory is fairly recent, compare, for example, C.Kitch, 'Anniversary Journalism, Collective Memory, and the Cultural Authority to Tell the Story of the American Past', Journal of Popular Culture, 36, 2002, pp. 44-67; N.Van House and E.Churchill, 'Technologies of Memory: Key Issues and Critical Perspectives', Memory Studies, 6, 2008, pp. 295310.

40. See <http://newsroom.fb.com/products/>

41. B.Taylor, 'The Next Evolution of Facebook Platform', Facebook Developers Blog, 2010, $<$ http://developers.facebook.com/blog/post/377/> For more technical information on the Open Graph protocol, see <http://opg.me/>, and for critical commentary on platforms, see R.Bodle, 'Regimes of Sharing: Open APIs, Interoperability and Facebook', Information, Communication $\mathcal{E}$ Society, 14, 2011, pp. 320-37; J.Van Dijck, 'Facebook as a Tool for Producing Sociality and Connectivity', Television and Media, 13, 2012, pp. 160-76; and Volume 14 of Culture Machine, 2013, entitled 'Platform Politics'.

42. T.Bucher, 'A Technicity of Attention: How Software "Makes Sense"', Culture Machine, 13, 2012, p. 5.

43. D.Massey, 'A Global Sense of Place', Marxism Today, June, p. 28.

44. Bucher, 'Technicity of Attention', p. 6.

45. M.Zuckerberg, Keynote, f8 Developers Conference, 22 September 2011. A video recording https://apps.facebook.com/feightlive/ (requires log-in)

46. For more discussion, see Bucher, 'Technicity of Attention', pp. 7-11.

47. The value of a given relationship in Facebook is, broadly, calculated by three factors: 'affinity', 'weight' and 'time decay'. The 'affinity' is determined according to the strength of a connection between two 'nodes'. If one user regularly views another's profile then the affinity is judged to be higher than if there is little recorded activity between them. The 'weight' is determined according to the kind of 'edge' between the 'nodes', for example, a 'Like' is less than a comment or a photo. 'Time decay' is determined as the 'age' of the 'edge', how much time has passed since its entry into the database. See J.Kincaid, 'EdgeRank: The Secret Sauce That Makes Facebooks News Feed Tick', TechCrunch, 22 April 2010, <http://techcrunch.com/2010/04/22/facebook-edgerank/>; Zuckerberg, Keynote; M.Tonkelwitz, 'Interesting News, Any Time You Visit', Facebook Blog, 20 September 2011, <https:/ / blog.facebook.com/blog.php?post=10150286921207131>

48. On 'discursive regimes', see M.Foucault, 'Truth and Power', in C.Gordon (ed.), Power/Knowledge. Selected Interviews and Other Writings, 1972-1977, trans. by C.Gordon, L.Marshall, J.Mepham and K.Soper (New York: Pantheon, 1980), p. 119. In relation to computation and software, see also: Kitchin and Dodge, Code/Space, pp. 18-20.

49. R.Kitchin, 'The Real-Time City? Big Data and Smart Urbanism', GeoJournal, 79, 2014, pp. 1-14; M.Shepard, Sentient City: Ubiquitous Computing, Architecture and the Future of Urban Space (Cambridge: The MIT Press, 2011).

50. A.Galloway, 'Intimations of Everyday Life: Ubiquitous Computing and the City', Cultural Studies, 18, 2004, pp. 384-408; S.Kinsley, 'Futures in the Making: Practices to Anticipate "Ubiquitous Computing"', Environment and Planning A, 44, 2012, pp. 1554-69.

51. Graham and Marvin, Splintering Urbanism; Graham, 'Software-Sorted Geographies'; R.Kitchin, 'The Programmable City', Environment and Planning B: Planning \& Design, 38, 2011, pp. 945-51.

52. M.Batty, 'Smart Cities, Big Data', Environment and Planning B: Planning \& Design, 39, 2012, pp. 19193.

53. H.Miller, ‘The Data Avalanche Is Here. Shouldn't We Be Digging?', Journal of Regional Science, 50, 2010, pp. 181-201.

54. See Kitchin, 'The Real-Time City?'.

55. See Kitchin, 'The Real-Time City?', pp. 4-5.

56. See Kitchin, 'The Real-Time City?'; see also: D.Boyd and K.Crawford, 'Critical Questions for Big Data', Information, Communication \& Society, 15, 2012, pp. 662-79; J.Manyika, M.Chui, B.Brown, J.Bughin, R.Dobbs, C.Roxburgh and A.H.Byers, Big Data: The Next Frontier for Innovation, Competition and Productivity (New York: McKinsey Global Institute, 2011); P.C.Zikipoulos, C.Eaton, D.deRoos, T.Deutsch and G.Lapis, Understanding Big Data (New York: McGraw-Hill, 2012).

57. In San Francisco, the Municipal Transportation Agency has trialled a demand-responsive meter system they call 'SFpark' that uses wireless sensors to detect parking space occupancy. Drivers can see available spaces, in real-time, using an online map - either on their website or through a 
free app. Pricing is adjusted according to measured demand, but adjustments are no more than 50 cents down and 25 cents up per hour in one month. See <http://sfpark.org/how-it-works/>

58. M.Batty, K.W.Axhausen, F.Giannotti, A.Pozdnoukhov, A.Bazzani, M.Wachowicz, G.Ouzounis and Y.Portugali, 'Smart Cities of the Future', European Physical Journal Special Topics, 214, 2012, p. 482.

59. See <http://www.quividi.com/>

60. Amscreen, 'Face Detection Technology to Revolutionise Advertising Industry', 8 July 2013, $<$ http://www.amscreen.eu/en/news-1/face-detection-technology-to-revolutionise-advertisingindustry $>$

61. See < http://www.pathintelligence.com/technology/ >

62. See <http://www.pathintelligence.com/services/optimise-shopper-experience/> and <http://www.shoppertrak.com/solutions/performance-analytics/>

63. See K.Wagstaff, 'Will Your Mall be Tracking Your Cellphone Today?', Time, 25 November 2011, <http:/ / techland.time.com/2011/11/25/will-your-mall-be-tracking-your-cellphone-today/>;

S.Datoo 'High Street Shops are Studying Shopper Behaviour by Tracking Their Smartphones or Movement', The Guardian, 3 October 2013, <http://www.theguardian.com/news/datablog/2013/oct/03/analytics-amazon-retailers-

physical-cookies-high-street>; See also Apple's addition to their mobile operating system, iOS, for customer tracking, called 'iBeacon': <http://support.apple.com/kb/HT6048>; and: $<$ https://developer.apple.com/ibeacon/>

64. B.Stiegler, 'Anamnesis and Hypomnesis: The Memories of Desire', in A.Bradley and L.Armand (eds), Technicity, trans. by F.Gleyzon (Prague: Charles University Press, 2007), p. 17.

65. Stiegler, 'Anamnesis and Hypomnesis', p. 19.

66. The theory of technogenesis offered by a range of anthropologists and philosophers posits that what we understand as 'human' and 'technology' have co-evolved together, that you do not get one without the other. See, for example: K.Hayles, How We Think: Digital Media and Contemporary Technogenesis, (Chicago: University of Chicago Press, 2012); B.Stiegler, Taking Care of Youth and the Generations, trans. S.Barker, (Stanford: Stanford University Press, 2010); B.Stiegler, Symbolic Misery. Volume 1: The Hyperindustrial Epoch, trans. B.Norman (Cambridge: Polity Press, 2014).

67. J.Ash, 'Technology, Technicity, and Emerging Practices of Temporal Sensitivity in Videogames', Environment and Planning A, 44, 2012, pp. 187-203; J.Ash, 'Technology and Affect: Towards a Theory of Inorganically Organised Objects', Emotion, Space and Society. Epub ahead of print 4 February 2014. DOI: 10.1016/j.emospa.2013.12.017; S.Kinsley, 'The Matter of Virtual Geographies', Progress in Human Geography, 38, 2014, pp. 364-85.

68. Stiegler, Technics and Time, 2, p. 4.

69. In the Preface to B.Stiegler, Technics and Time, 1. The Fault of Epimetheus, trans. by R.Beardsworth and G.Collins (Stanford: Stanford University Press, 1998).

70. G.Simondon, 'Technical Mentality', Parrhesia, 7, 2009, pp. 17-27.

71. For an accessible introduction to Stiegler's theory of 'mnemotechnics', see B.Stiegler, For a New Critique of Political Economy, trans. by D.Ross (Cambridge: Polity Press, 2010), pp. 8-11. See also: Stiegler, Technics and Time, 2, pp. 4-6; P.Crogan 'Bernard Stiegler: Philosophy, Technics and Activism', Cultural Politics, 6, 2010, pp. 133-156.

72. See in particular the first part of Stiegler, Technics and Time, 1.

73. E.Husserl, On the Phenomenology of the Consciousness of Internal Time, trans. by J.B.Brough (Boston: Kluwer Academic Publishers, 1991).

74. Stiegler, For a New Critique, pp. 8-9.

75. Stiegler, For a New Critique, p. 9.

76. See Y-F.Tuan, Space and Place: The Perspective of Experience (Minneapolis: University of Minnesota Press, 1977); D.Harvey, 'From Space to Place and Back Again', in J.Bird, B.Curtis, T.Putnam, G.Robertson and L.Tickner (eds), Mapping the Futures: Local Cultures Global Change (London: Routledge, 1993), pp. 2-29.

77. See, in particular, Stiegler, Technics and Time, 2; Stiegler, Technics and Time, 3 and the development of those arguments in Chapter 3, 'Allegory of the Anthill', in Stiegler, Symbolic Misery, pp. 45-80.

78. See, in particular, Stiegler, Technics and Time, 2 and Stiegler, Technics and Time, 3.

79. Stiegler, Technics and Time, 2, pp. 115-8.

80. Stiegler, Technics and Time, 2, p. 116.

81. For more detailed discussion about the process of cultivating attention and how this has become commoditised, see P.Crogan and S.Kinsley, 'Paying Attention: Towards a Critique of the Attention Economy',

Culture

Machine,

13, 2012 
http://www.culturemachine.net/index.php/cm/article/view/463/500>; B.Stiegler, 'Relational Ecology and the Digital Pharmakon', Culture Machine, 13, $2012<$ http://www.culturemachine.net/index.php/cm/article/view/464/501>; B.Stiegler, Taking Care of Youth and the Generations.

82. Stiegler, Technics and Time, 2, p. 120.

83. Stiegler, Technics and Time, 2, p. 120.

84. Stiegler, Technics and Time, 2, p. 120.

85. I.James, The New French Philosophy (Cambridge: Polity Press, 2012), p. 69.

86. J.Pickles, A History of Spaces. Cartographic Reason, Mapping and the Geo-Coded World (Oxford: Routledge, 2004), p. 146.

87. In the sense of the complimentary, if rather different, theorisation of the work of memory to the work of Stiegler that is presented in J.Derrida, Memoires for Paul de Man (New York: Columbia University Press, 1986); J.Derrida, 'Archive Fever. A Freudian Impression', Diacritics, 25, 1995, pp. 9-63.

88. D.Mitchell, 'Cultural Landscapes: Just Landscapes or Landscapes of Justice?', Progress in Human Geography, 27, 2003, p. 790; see also: J.Wylie, Landscape (Oxford: Routledge, 2007), pp. 191-4.

89. Wylie, Landscape, citing: G.Henderson, 'What (else) We Talk about When We Talk about Landscape: For a Return to the Social Imagination', in C.Wilson and P.Groth (eds), Everyday America: Cultural Landscape Studies after J.B. Jackson (Berkeley: University of California Press, 2003), p. 189.

90. Mitchell, 'Cultural Landscapes', citing Henderson, 'What (else) We Talk about When We Talk about Landscape', p. 192; for further discussion, see also D.Cosgrove, 'Landscape and the European Sense of Space - Eyeing Nature', in K.Anderson, M.Domosh, S.Pile and N.Thrift (eds) Handbook of Cultural Geography (London: SAGE, 2003), pp. 249-68.

91. K.Hetherington, 'In Place of Geometry: The Materiality of Place', in K.Hetherington and R.Monro (eds), Ideas of Difference (Oxford: Blackwell, 1997), p. 189.

92. J.Wylie, 'Depths and Folds: On Landscape and the Gazing Subject', Environment and Planning D: Society E Space, 24, 2006, pp. 519-35.

93. Kitchin and Dodge, Code/Space.

94. Wylie, 'Depths and Folds', p. 531.

95. Kitchin and Dodge, Code/Space, p. 71.

96. Kitchin and Dodge, Code/Space, p. 72.

97. B.Stiegler, The Decadence of Industrial Democracies: Disbelief and Discredit, vol. 1, trans. by D.Ross (Cambridge: Polity Press, 2011), p. 38; further discussed in Kinsley, 'The Matter of 'Virtual' Geographies', pp. 374-6.

98. Massey 'A Global Sense of Place', p. 25.

99. M.Augé, Non-places: Introduction to an anthropology of supermodernity, trans. by J.Howe (London: Verso, 1995).

100.A.Mackenzie and R.McNally, 'Living Multiples: How Large-Scale Scientific Data-Mining Pursues Identity and Differences', Theory, Culture E Society, 30, 2013, p. 73.

\section{Author biography}

Samuel Kinsley is a Lecturer in Human Geography at the University of Exeter. His teaching, research and associated writing examine the cultural politics, material experience and spatial imaginations of technology. 